\title{
Geografia Econômica e Reestruturação Espacial Contemporânea: Passado e Presente, Desenvolvimento e Utopística
}

\section{Leandro Dias de Oliveira}

\author{
(2) OpenEdition \\ Journals \\ Edição electrónica \\ URL: http://journals.openedition.org/espacoeconomia/855 \\ DOI: 10.4000/espacoeconomia.855 \\ ISSN: 2317-7837 \\ Editora \\ Núcleo de Pesquisa Espaço \& Economia

\section{Refêrencia eletrónica} \\ Leandro Dias de Oliveira, « Geografia Econômica e Reestruturação Espacial Contemporânea: Passado \\ e Presente, Desenvolvimento e Utopística », Espaço e Economia [Online], 4 | 2014, posto online no dia \\ 11 setembro 2014, consultado o 22 setembro 2020. URL : http://journals.openedition.org/ \\ espacoeconomia/855 ; DOI : https://doi.org/10.4000/espacoeconomia.855
}

Este documento foi criado de forma automática no dia 22 setembro 2020.

\section{(c) NUPEE}




\title{
Geografia Econômica e Reestruturação Espacial Contemporânea: Passado e Presente, Desenvolvimento e Utopística
}

\author{
Leandro Dias de Oliveira
}

1 Os economistas portugueses José Pedro Pontes e Regina Salvador (2009) - da School of Economics \& Managements da Universidade de Lisboa e do Departamento de Geografia e Planeamento Regional da Universidade de Nova Lisboa, respectivamente - no trabalho intitulado "A Nova Geografia Econômica", analisam com proficuidade os desafios interpretativos deste subcampo disciplinar que aproxima Economia e Geografia, os quais podemos assim sintetizar: [i] compreender o processo de globalização, em suas faces econômica e financeira, o papel das multinacionais, a crescente mobilidade da produção, entre outros, e a criação de uma nova estrutura que rompe com a velha e conhecida relação "Estado=Território=Riqueza"; [ii] apreender o crescente desaparecimento da fronteira entre economia internacional e economia regional, o que permitiu tanto no "Velho" quanto "Novo" Mundo a redescoberta do papel do espaço na atividade econômica; e, por fim, [iii] aprofundar o estudo da localização das atividades econômicas, tratando da competitividade entre cidades e regiões, acrescido de análise teórica e empírica.

2 É patente, mediante a leitura dos autores, que vivemos tempos de reestruturação econômica e espacial que devem ser analisadas de maneira entrelaçada: econômica, com a emersão de um novo modelo produtivo (HARVEY, 1992 [1989]; HOOGVELT, 1997, entre outros) e as diversas mutações na própria economia política com o alargamento interpretativo do sistema estatocêntrico westphaliano; e espacial, numa nova cadeia de cidades-força e uma miríade de redes (des)territorializadas de mercadorias, pessoas, informações e tecnologia (HAESBAERT, 2004). Todavia, neste capitalismo industrialfinanceiro - como assevera François Chesnais (1996 [1994], p. 241), "os capitais que se valorizam na esfera financeira nasceram e continuam nascendo no setor produtivo" - não se 
trata tão somente do alargamento das bases espaciais e a emersão de novos modelos produtivos, nem tampouco a simples evolução do fordismo para um regime de acumulação flexível (HARVEY, op. cit.) (ou "ohnoísmo", "toyotismo", "neofordismo", entre tantos outros qualificativos), mas sim de uma renovação ideológica da indústria contemporânea, que se oculta - as gigantescas plantas fabris submergem em áreas menos visíveis ao cotidiano da metrópole e das grandes cidades (em verdadeiros esconderijos espaciais!) - e se propõe menos opressora para com a natureza.

3 Assistimos a tempos rápidos [insistimos aqui na efemeridade dos acontecimentos no presente, desde o ciclo da mercadoria até mesmo na (geo)política, cultura e economia] com mudanças profundas na realidade espacial. E tempos de reestruturação produtivo-territorial exigem a prática de uma geografia econômica em ritmo analítico capaz de compreender o imediato, o fugaz, os ritmos virtuais dos superfluxos globais, e não uma leitura da economia espacial em marcha-forçada ou mesmo em moto-contínuo.

4 Reestruturação espacial contemporânea, segundo nossa interpretação, pode ser compreendida como o movimento engendrado hegemonicamente de adaptação do sistema produtivo a duas necessidades prementes: [1] um ajuste econômico-ambiental, com a adoção do modelo de desenvolvimento sustentável em substituição à obliteração acelerada da natureza, cuja base é geopolítica e que se consolida enquanto nutriz ideológica; [2] o processo de reestruturação territorial-produtiva, com o acerto do tempo do negócio fabril, seja com o just-in-time imposto à mercadoria e ao trabalhador, seja com o consumo dos bens que já nascem obsoletos ou do próprio território, cujos reflexos espaciais somente agora são verdadeiramente reconhecidos. Ajustando homem e natureza, tempo e espaço, tecnologia e necessidades produtivas, os dois processos ideológicos acima delineados não são antagônicos, mas complementares: o trabalhador deve ser ambientalmente educado e flexível, a fábrica ecologicamente correta e renovada em seu modelo industrial, e a cidade sustentável e pós-moderno-industrial.

5 Entender este processo e suas contradições, sem perder o horizonte da utopística noção de Immanuel Wallerstein (2003 [1998]) para a necessidade de uma avaliação e julgamento das alternativas históricas; uma reconciliação entre ciência e utopia; uma perspectiva de transformação socialmente qualitativa - é fundamental para a Geografia Econômica do tempo presente. Assim, Espaço \& Economia: Revista Brasileira de Geografia Econômica, periódico que agora apresentamos em seu quarto número, permanece com seu inadiável desafio: promover uma geografia econômica viva, capaz de pensar o presente, entendido como elo entre passado e futuro.

6 Passado e presente, momentos históricos que se confundem na pesquisa que abre a seção Artigos: "Mapeamento do trabalho escravo contemporâneo no Brasil: Dinâmicas Recentes", de autoria dos professores Eduardo Paulon Girardi (Unesp), Neli Aparecida de Mello-Théry (USP), Hervé Théry (CNRS / USP) e Julio Hato (USP). Os autores tratam, a partir da investigação dos dados levantados particularmente pela CPT (Comissão Pastoral da Terra) e pelo MTE (Ministério do Trabalho e Emprego), do fenômeno da escravidão no Brasil contemporâneo. Na era do homem-flexível (KURZ, 1999), tratar de escravidão - em sentido literal, com o homem desumanizado, coisificado - como algo contemporâneo é assustador ${ }^{1}$. É uma torpe combinação da pobreza dos trabalhadores de origem rural (sem terra ou desintegrados) com o poder político econômico e mentalidade feudal dos fazendeiros que empregam a prática em verdadeiros esconderijos espaciais. 
7 Segundo o trabalho, é nas regiões Norte [Amazônica, se preferirmos a classificação em Regiões Geoeconômicas de Pinchas Geiger (1969 e 1970)] e Nordeste que a prática da escravidão é substantiva, o que revela, por exemplo, o desflorestamento da borda amazônica e expansão da fronteira agrícola, junto a toda a economia de aglomeração resultante disso. Os trabalhadores escravos vão realizar, numa espécie de reedição histórica dos tempos feudais, aquelas atividades que são indignas e perigosas, sobretudo em companhias siderúrgicas, carvoarias, mineradoras, madeireiras, usinas de álcool e açúcar, destilarias, empresas de colonização, garimpos, entre muitas outras descritas no trabalho. Assim, torna-se fácil constatar, por exemplo, que a problemática ambiental contemporânea é também - ou acima de tudo! - um problema de ordem social.

Uma geografia econômica da escravidão! Espacialização do trabalho, redes de tráfico humano, localização e tipologia econômica, desflorestamento e demais impactos ambientais na escala da região; mais que rugosidades (SANTOS, 2002 [1996]), isto mostra o quanto a Geografia Econômica precisa olhar o presente e o futuro, mas sem abdicar de enfrentar as questões teóricas do passado. O capitalismo cada vez mais revela suas contradições espaço-temporais, e possivelmente esteja aí seu principal artifício de sobrevivência.

9 A seguir, Leandro Dias de Oliveira, professor da UFRRJ - Universidade Federal Rural do Rio de Janeiro, apresenta "Rio + 20: Reflexões sobre geopolítica e ideologia", esforço analítico que pretende interpretar, à luz da geopolítica e da geoeconomia, o histórico, o espectro político e os desdobramentos imediatos da Conferência das Nações Unidas sobre Desenvolvimento Sustentável (conhecida como Rio + 20), que ocorreu entre os dias 13 e 22 de junho de 2012 na cidade do Rio de Janeiro. Vale ressaltar que esta megaconferência superou em número de delegações oficiais a Rio-92 (ou Eco-92) [Conferência das Nações Unidas sobre Meio Ambiente e Desenvolvimento, Rio de Janeiro, Brasil, 1992] e a Cúpula do Milênio [Nova Iorque, Estados Unidos, 2000], se tornando a maior de todos os tempos, ao totalizar a participação de representantes de 193 países, com a presença de mais de 100 chefes de Estado e de Governo e aproximadamente 12.000 delegados oficiais. 0 número total de participantes oficiais na Cúpula das Delegações, realizada no Centro de Convenções - Riocentro, foi de 45.381 pessoas.

10 Trata-se da continuidade da investigação do autor acerca da Geopolítica do Desenvolvimento Sustentável, cuja compreensão extravasa a insípida definição contida no Relatório Brundtland, de 1987, em que se lê que este modelo de desenvolvimento é aquele que atente "as necessidades do presente sem comprometer a possibilidade de as gerações futuras atenderem as suas próprias necessidades" (BRUNDTLAND, 1988 [1987], p. 46). Esta noção é vaga, imprecisa e maliciosa por sua maleabilidade política e econômica; por este motivo, está presente no artigo uma leitura tripartite, na qual o desenvolvimento sustentável corresponde: [i] a um acerto de ordem geopolítica, através de diversos protocolos, para a manutenção de riquezas naturais contidas particularmente nos países da periferia; [ii] a uma fórmula de racionalidade instrumental da natureza - vista como recurso, mercadoria e capital futuro - pelo próprio modelo industrial-capitalista; e, por fim, [iii] a uma ideologia contemporânea, de grande capacidade de sedução e diapasão.

11 É possível afirmar que em um intermezzo de dez-quinze anos, a concepção de desenvolvimento sustentável deixou de representar uma solução muito bem-vinda para os problemas ecológicos mundiais para ser objeto de desconfiança. Mas, ainda que a 
massa crítica tenha neste curto intervalo de tempo notado o quanto é limitada esta opção de desenvolvimento, no campo político-econômico este modelo se consolidou de tal maneira que se tornou lugar-comum. A crítica ao desenvolvimento sustentável, à revelia do que possa parecer, nunca foi tão urgente quanto nos dias atuais, pois se consolidou como ideologia e, de certo modo, assumiu uma postura mais agressiva, como se notou na Rio + 20, voltada para a construção de uma "economia verde".

Mateus Monteiro Lobato, doutorando em geografia da Universidade Estadual Paulista (UNESP) - campus Presidente Prudente, e Marília Ferreira Emmi, professora da Universidade Federal do Pará (UFPA), assinam o terceiro artigo da revista, com o título "Globalização e reestruturação espacial na fronteira: 0 impacto da implantação de grandes obras na cidade de Marabá (PA)". Trata-se de um texto que versa sobre as transformações geoeconômicas que vive a cidade média de Marabá, que receberá, entre outros aportes econômico-territoriais, obras de infraestrutura de grande porte, como a Aços Laminados do Pará (ALPA) - na margem direita do rio Tocantins, em uma área já foi limpa e recebeu obras para terraplenagem -, a construção de shoppings e a duplicação de uma rodovia federal e da estrada de ferro Carajás.

Partindo do conceito de fronteira - que, definitivamente, deve ser compreendida de forma autonomizada das linhas divisórias contidas nos mapas - os autores abordam o potencial econômico-logístico das franjas amazônicas, com novos veios de transporte, de movimento de pessoas e de interligações econômicas. Afinal, a cidade de Marabá exerce uma função importante dentro da rede urbana do sul e sudeste paraense e entorno, e sua centralidade foi construída com termos políticos, econômicos e logísticos. E no que se refere à fronteira econômica da Região Amazônica, há muito o Banco Mundial vem operando, financiando intervenções diversas [salientamos que geralmente são ambientalmente incorretas, ainda que carreguem consigo o signo da "sustentabilidade"] e vai paulatinamente impondo um papel regional de produtor de agro-minero-florestais (gado, madeira, minério e soja). Uma Rodovia Transamazônica com novos condomínios sofisticados e margeada por empreendimentos industriais é a paisagem que se desenha, segundo os autores, para os próximos anos.

a seção de artigos, Auro Aparecido Mendes, professor do Departamento de Geografia da UNESP-Rio Claro apresenta "Condomínios Industriais em Atibaia SP: O Espaço mudando a Indústria e as Políticas Territoriais". $\mathrm{O}$ autor se debruça sobre a formação de condomínios industriais, que traz para o mundo da fábrica a valorização de formas compartilhadas de propriedade e cogestão do espaço, da logística e da própria absorção de bens tanto tangíveis (matérias-primas naturais, mercadorias) quanto imateriais ou intangíveis (troca de informações ou conhecimento).

Seu trabalho alimenta o debate sobre o processo de reestruturação produtiva em curso, que significou uma profunda mudança na própria espacialização da indústria, uma vez que assistimos a um momento de transformação do modelo produtivo-industrial com características comuns ao fordismo, mas que desconstrói o antigo padrão de grandes plantas fabris, de cidades operárias, de desenvolvimento nacionalista e de produção em larga escala e em série. Em tempos de globalização e meio técnico-científicoinformacional, tem início um profundo processo de tecnificação espacial que prioriza as redes técnicas e comunicacionais, bem como a efetivação de tecnopolos, clusters, bunkers e condomínios industriais. Observamos, na contemporaneidade, a emersão de uma nova geografia da indústria, com a emersão de um diferente modelo de estruturação territorial. 
16 Assim, Auro Mendes nos apresenta este padrão condominial de indústria através do estudo de caso do "Vale do Silício Brasileiro" (Região Metropolitana de Campinas), que agrega uma "tecnopolização" por meio das trocas de expertises do Centro de Pesquisa e Desenvolvimento (CPqD) da Telebrás, o Instituto Nacional de Tecnologia da Informação (ITI) e as unidades de pesquisa da Embrapa, além das universidades Puccamp (Pontifícia Universidade Católica de Campinas) e Unicamp (Universidade Estadual de Campinas). As margens da Rodovia D. Pedro I - o corredor de exportação mais importante do país agregam diversos investimentos industriais recentes, confirmando assim a importância do "burburinho", indicado por Michael Storper e Anthony Venables (2005) para confirmar a atual força econômica da cidade. O "burburinho" - ou FaF (contato Face a Face, se preferirmos uma noção mais metodológica) - é a causa e resultado dos transbordamentos tecnológicos e de conhecimentos; é uma construção eminentemente humana de "contato visual" e "proximidade emocional" que vai além da detecção de mensagens visuais e corpóreas; é uma tecnologia-chave da comunicação, algo motivante, psicológico e físico. Esta troca de feedbacks, ímpetos, esforços, monitoramentos e julgamentos recria e reforça a aglomeração industrial em novas bases explicativas.

17 Já na seção Trilhas de Pesquisa, Felipe de Souza Ramão, mestrando em Geografia da Universidade do Estado do Rio de Janeiro - Faculdade de Formação de Professores, apresenta "A privatização do meio ambiente na cidade de Cabo Frio: Uma reflexão a partir das contribuições de Pierre George". Neste trabalho, notamos como a retomada das reflexões do geógrafo francês Pierre George, da corrente crítico-marxista, é fundamental para os militantes da Geografia Econômica e da Indústria (Ver Guglielmo, 2008): a noção de meio ambiente e sua adequação capitalista, através da emersão de um "sistema verde", uma nova mitologia ruralista em oposição à cidade poluída, o turismo e a fuga da metrópole para cidades menores são apenas alguns exemplos da capacidade analítica e visionária de George, e por que não, da própria Geografia, em interpretar o presente com o olhar no futuro.

18 Neste artigo, a obra de Pierre George auxilia metologicamente o autor na compreensão das transformações urbanas da cidade de Cabo Frio, localizada na Região dos Lagos Fluminense. Cabo Frio é uma cidade média, que assiste seu crescimento econômico e modernização de forma combinada às retomadas da tradicionalidade nativa e seus reacionarismo (OLIVEIRA, RIBEIRO, 2009), e tem no turismo praiano [junto ao petrorrentismo, vale destacar] a principal atividade econômica. Assim, caminha-se da proteção à espetacularização do meio ambiente, com a explosão de investimentos que vão das reformas das orlas marítimas à implantação de inúmeros novos hotéis, tornando as belezas naturais fatores funtamentais de crescimento econômico e obtenção de lucros.

19 Já a leitura de "A importância dos estudos sobre interiorização da universidade $e$ reestruturação territorial", de autoria de Leonardo Chagas de Brito, doutorando do IPPUR-UFRJ, permite aproximar os novos conteúdos da reestruturação territorial em curso no Estado do Rio de Janeiro com a expansão do número de Instituições de Ensino Superior (IES) públicas no interior do estado fluminense.

20 Se na década de (19)90 foi uma instituição estadual, a UERJ, que mais interiorizou e expandiu - resultado, particularmente, da retroação das unidades federais medeiante o horizonte econômico neoliberal do Governo Federal neste período -, na década de 2000 foram as instituições de ensino superior federais do Rio de Janeiro, como UFRJ, UFF e 
UFRRJ, que lideraram tais processos, devido particularmente ao REUNI (Reestruturação e Expansão das Universidades Federais), política pública presente na gestão Luís Inácio Lula da Silva e mantida pela administração de Dilma Rousseff.

21 Mas, como alerta Leonadro Brito, não é somente este o vetor explicativo: a reestruturação produtiva fluminense, no que se refere à aplicação de tecnologia no interior da fábrica, a diversificação da produção e a localização de novos empreendimentos a partir do paradigma das vantagens comparativas; as mudanças no mundo do trabalho, além dos avanços tecnológicos nos meios de comunicação e transporte; a demanda simbólica e a expansão / intensificação da urbanidade do interior fluminense são fatores preponderantes para a interiorização das Instituições de Ensino Superior públicas no estado do Rio de Janeiro. Neste caso, ideologicamente, o ensino superior se oferece como fator de progresso, de desenvolvimento e integração e, sobretudo, como fator de status e prestígio; o autor reforça este caráter emblemático do ensino superior, que se sobrepõe até mesmo à criação de intelligentsias regionais ou mesmo à alimentação de tecnopolos para além da metrópole.

A quarta edição de Espaço \& Economia abriga duas resenhas. A primeira, intitulada "A porta sublime e o início do século XX", de Breno Viotto Pedrosa, Professor da Universidade Federal da Integração Latino-Americana (UNILA), corresponde à leitura de "O expresso Berlim-Bagdá - o Império Otomano e a tentativa da Alemanha de conquistar o poder mundial 1898-1918", de Sean McMeekin (São Paulo: Editora Globo, 2011). O resenhista entende a obra como elucidativa sobre a geopolítica e a conformação da Primeira Guerra Mundial para além do olhar europeu. A Primeira Grande Guerra torna-se assim uma possível chave explicativa para muitos dos acontecimentos, conflitos e tensões do chamado Oriente Médio.

23 É interessante olhar com as lentes da geografia o processo de escolha do trajeto e construção da ferrovia que deveria ligar Berlim até Bagdá, passando justamente pelos Bálcãs e pela região da Anatólia ao Iraque, oferecendo uma ligação entre o mar do Norte e o Golfo Pérsico. Sem tecnologia suficiente, o império otomano utilizou o projeto para inserir ramais secundários para ligações rumo às cidades sagradas de Meca e Medina, de modo a concorrer com o império britânico que coordenava grandes fluxos de peregrinos religiosos.

24 A segunda resenha, referente à leitura de "Geografia e Geopolítica do Petróleo", organizado por Frédéric Monié e Jacob Binsztock (Rio de Janeiro: Mauad, 2012), é de Mariana Ribeiro Fernandes, graduada em Relações Internacionais pela UFRRJ, e se intitula "A questão do petróleo no Brasil: reflexões sobre o cenário atual". A resenhista, vinculada ao Grupo de Pesquisa "Reestruturação Espacial Contemporânea" (UFRRJ), rompe com certa negligência dos profissionais de Relações Internacionais para com o tema da influência da posse do petróleo e suas técnicas no âmbito internacional, e justifica a importância deste debate lembrando que: a ONU delibera sobre medidas, sanções e resoluções que envolvem petróleo; ocorrem mobilizações contra a exploração de reservas petrolíferas (no Mar do Norte, por exemplo); e acordos comerciais sobre o comércio do ouro negro são firmados, bem como concessões, leilões e troca de tecnologias entre governos e multinacionais; fatos como estes tornam o tema fundamental para a compreensão da ordem internacional vigente.

25 Mariana Fernandes aponta que "Geografia e Geopolítica do Petróleo" é uma coletânea de artigos que abordam a questão do petróleo não de maneira técnica, mas política: as implicações deste no comércio nacional e internacional, a garantia de fontes 
petrolíferas no status de potência e nas estratégias estatais, bem como os impactos domésticos que uma descoberta de jazida petrolífera pode causar para o Estado que a encontra. $\mathrm{O}$ tema é tratado no livro de maneira que abrange diversas escalas: o nível global, o regional e, por fim, o local, e traz informações valiosas sobre, por exemplo, as mudanças ocorridas nas cidades do norte do estado do Rio de Janeiro, em virtude do petrorrentismo e da descoberta da camada pré-sal.

Esta edição de Espaço \& Economia inclui ainda a seção Notas, com a reflexão intitulada "Conferência dos BRICS produz início de um consenso capaz de abrir uma nova era para a humanidade apesar dos seus inimigos", assinada por José Carlos de Assis, Luiz Pinguelli Rosa, Darc Antônio Costa, Dércio Garcia Munhoz, Samuel Pinheiro Guimarães, Severino Cabral e Theotônio dos Santos. Trata-se de uma profícua análise do documento "Consenso do Rio", resultado da Conferência BRICS no Século XXI, que reuniu no Rio, de 20 a 23 de maio, especialistas de Brasil, Rússia, Índia, China e África do Sul, em busca do desenvolvimento econômico como esteio do desenvolvimento social com sustentabilidade ambiental. Com estatuto de bloco econômico, os BRICS se consolidam como um novo ponto de inflexão na ordem internacional contemporânea, e pauta de destaque na geografia econômica que se pratica.

Agradecemos, em nome dos demais editores e dos membros dos comitês científico e consultivo, a todos aqueles que se predispuseram a contribuir, na condição de autores, resenhistas, pareceristas e revisores, de maneira tão competente quanto gentil. Assim, Espaço \& Economia: Revista Brasileira de Geografia Econômica reforça seu caráter de esforço coletivo e de trabalho conjunto, e renova seu compromisso com olhar crítico e questionador.

\section{BIBLIOGRAFIA}

BRUNDTLAND, Gro Harlem. COMISSÃO MUNDIAL SOBRE MEIO AMBIENTE E DESENVOLVIMENTO

- 1988. Nosso Futuro Comum (Relatório Brundtland). Rio de Janeiro: Fundação Getúlio Vargas, 1988 [1987].

CHESNAIS, François. A mundialização do Capital. São Paulo: Xamã, 1996 [1994].

GUGLIELMO, Raymond. Pierre George, promoteur de la géographie industrielle. Cahiers de géographie du Québec. Volume 52, numéro 146, septembre 2008, p. 255-259. Disponível em: http:// www.erudit.org/revue/cgq/2008/v52/n146/019593ar.pdf. Acesso em: 20 de julho de 2014.

HAESBAERT, Rogério. 0 mito da desterritorialização: do "fim dos territórios" à multiterritorialidade. Rio de Janeiro: Bertrand Brasil, 2004.

HARVEY, David. Condição Pós-Moderna: uma pesquisa sobre as origens da mudança cultural. 13. ed. São Paulo: Loyola, 2004 [1989].

HOOGVELT, Ankie. Globalization and the PostColonial World: The New Political Economy of Development. Baltimore, Maryland: The Johns Hopkins University Press, 1997. 
KURZ, Robert. 0 Homem Flexível. Publicado na Folha de São Paulo em 11/07/1999 com o título Descartável e degradado. Disponível em: http://obeco.planetaclix.pt/rkurz11.htm. Acesso em 10 de junho de 2014 .

OLIVEIRA, Leandro Dias de; RIBEIRO, Guilherme. As territorialidades da metrópole no século XXI: tensões entre o tradicional e o moderno na cidade de Cabo Frio-RJ. Geo UERJ, v. 3, p. 108-127, 2009. Disponível em http://www.e-publicacoes.uerj.br/index.php/geouerj/article/viewFile/1431/1209. Acesso em 25 de julho de 2014.

PINCHAS GEIGER, Pedro. Regionalização. Revista Brasileira de Geografia. Vol. 31, noำ 1969.

PINCHAS GEIGER, Pedro. Divisão regional e o problema regional. Revista Brasileira de Geografia. Vol. $32, \mathrm{n}^{\circ} 2,1970$.

PONTES, José Pedro; SALVADOR, Regina. A Nova Geografia Econômica. In: COSTA, José Silva; NIJKAMP, Peter (Coord.) Compêndio de Economia Regional - Volume I: Teorias Temáticas e Políticas. Caiscais [Portugal], Editoria Princípia, 2009.

SANTOS, Milton. A Natureza do Espaço. Técnica e Tempo. Razão e Emoção. São Paulo: EDUSP, 2002 [Hucitec, 1996].

STORPER, Michael; VENABLES, Anthony. O Burburinho: a força econômica da cidade. In: CAMPOLINA DINIZ, Clélio; LEMOS, Mauro Borges. (Orgs.). Economia e Território. Belo Horizonte, Editora da UFMG, 2005.

WALLERSTEIN, Immanuel. Utopística ou As Decisões Históricas do Século Vinte e Um. Petrópolis - RJ, Editora Vozes, 2003 [1998].

\section{NOTAS}

1. Não compreender esta asserção como uma fetichização do homem-flexível, mas sim como a idiossincrasia que é coabitação do "trabalhador do capitalismo avançado", que já percorreu diversas etapas históricas, e o "escravo", uma forma pré-capitalista de sujeição do trabalhador em pleno século XXI.

\section{AUTOR}

\section{LEANDRO DIAS DE OLIVEIRA}

Doutor em Geografia pela UNICAMP - Universidade Estadual de Campinas. Professor de Geografia Econômica e da Indústria do Departamento de Geociências da UFRRJ - Universidade Federal Rural do Rio de Janeiro, e líder do Grupo de Pesquisa "Reestruturação Espacial Contemporânea". 